\title{
Dynamic Simulation for Three phase Induction Motor and Speed Control Using Matlab Simulink
}

\author{
P. Rajesh ${ }^{a}$, and M. Sharanya ${ }^{b}$ \\ A PG Student, Dept. of Electrical and Electronics Engineering, Coimbatore Institute of Technology, Coimbatore, Tamilnadu, \\ India. \\ ${ }^{\mathrm{b}}$ Professor, Dept. of Electrical and Electronics Engineering, Malla Reddy college of Engineering and \\ Technology,(Autonomous Campus), Hyderabad Telengana, India..
}

Article History: Received: 11 January 2021; Accepted: 27 February 2021; Published online: 5 April 2021

\begin{abstract}
The use of mechanical energy in daily life including industries and transport applications are increasing rapidly. Induction motor has special advantages because of less cost, reliable, robust and less maintenance when compared to other motors. It also has special features which satisfies all the requirements. On the whole 3-phase IM (Induction motor) plays major role in several applications (i.e. industrial, mechanical). The meticulous behavior of induction motor modeling and speed control can aid for controlling of machine application where flawless results can be obtained. The major faults in the IM effect the air gap flux, where the mathematical modeling can helpful to estimating the errors obtain while designing the motor. The paper represents the bit by bit implementation of 3-phase induction motor modeling and speed control using MATLAB simulation.
\end{abstract}

Keywords: 3-phase Induction motor, Simulink model, MATLAB, speed control.

\section{Introduction}

Before the creation of rotating magnetic field, motors are employed by continually passing a conductor through a constant magnetic field "as in homo polar motors" (Tripti Rai 2016). Tesla had proposed that the commutators from a electrical machine could be eliminated and the device could operate on a rotating magnetic field of force This classic AC (Alternating current) electro-magnetic motor was an IM (Ezhilarasi, 2020)

In the IM (induction motor), the armature and field were ideally of equal the field strengths and has field equal sizes. The combined energy provided to operate the device equals to addition of the energy stored in the field and armature coils (Rajalakshmi 2010). The power advance in device to operate is equals to the product of the energy stored in the field coils and armature. The main advantage is that IM (induction mot or asynchronous motor do not require an electrical connection between rotating and stationary parts of the motor (Arunkarthikeyan, 2021, Garikipati, 2021). Therefore, they don't need any mechanical commutators (brushes), going to the fact that induction motors are maintenance free motors. IM also have les sweight and inertia, huge overload capability and greater efficiency (Krause, 2002; Shahin, 2007; ChinnamahammadBhasha, 2020).

The operation principle of 3-phase IM (induction motor) is modelled to operate the steady state equivalent circuit and parameter calculation. Dynamic simulation is the one of key steps in endorsement of the motor-drive system and design process, which helps to eliminates the mistakes and errors resulting when prototype building and testing (Deepthi, 2019). The dynamic modeling of IM (induction motor) in quadrature, direct, and zerosequence axes can be evolved from fundamental expressions of transformation. When compared to other simulation tools MATLAB holds certain place in modelling of IM using $d q 0$ axis (Liang, 2002). The transformation uses different steps based on the simple trigonometric relationship obtained as projections on a set of axes (Arunkarthikeyan, 2020). The dynamic model is used to acquire small signal equations, transient responses and transfer function of induction motor. it also helps in modeling of all differential currents, voltages and flux linkages between moving rotor and stationary stator (Jayanthiladevi, 2018). And equations for torque, inertia and speed versus time. The modeling and speed control has been done by using MATLAB/Simulink which represents three phase d-q axis transformation and speed control using V/F(Sampathkumar, 2020; Balamurugan, 2018) . The advantage of using MATLAB is that we can compute electromagnetic dynamic model in a easy way and using function blocks it can be simulated faster. 


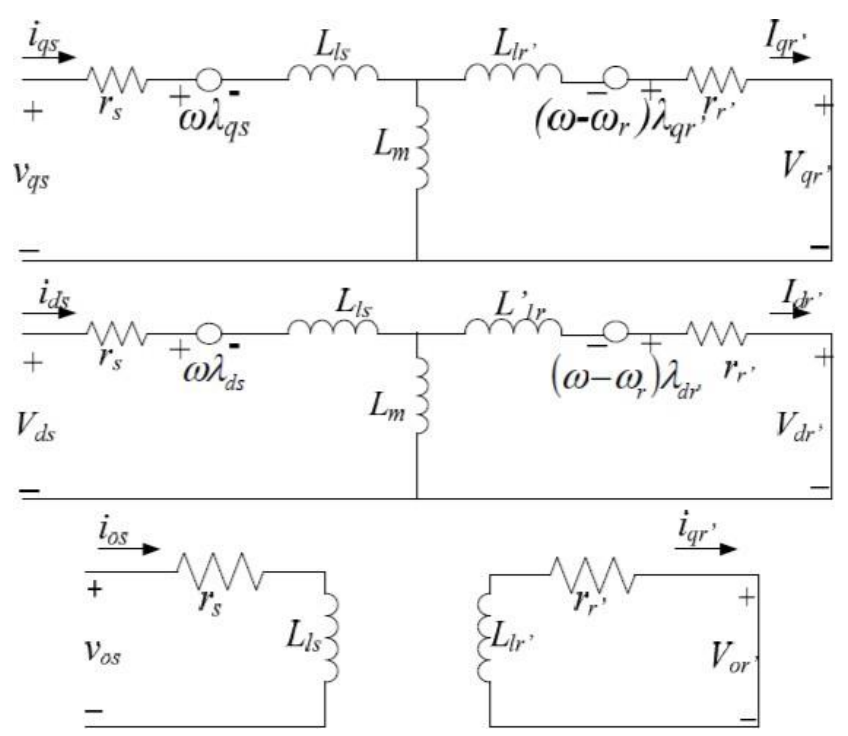

Figure 1. Three phase induction motor equivalent circuit.

\subsection{Nomenclature}

Vas, Vbs, Vcs

Input Voltages for phase $\mathrm{a}, \mathrm{b}$ and $\mathrm{c}$

respectively in Volts.

Stator $\mathrm{q}$ and $\mathrm{d}$ axis voltages in Stationary

Vqs, Vds

Vqr, Vdr

Iqs, Ids

Iqr, Idr

Rs

$\mathrm{Lm}$

$\mathrm{Rr}$

$\mathrm{Lr}$

$\mathrm{J}$

$\mathrm{Te}$

TL

reference frame respectively in Volts.

\section{Rotor $\mathrm{q}$ and $\mathrm{d}$ axis Voltages in Stationary}

reference frame respectively in Volts.

Stator $\mathrm{q}$ and $\mathrm{d}$ axis Currents in Stationary

reference frame respectively in A.

Rotor $\mathrm{q}$ and $\mathrm{d}$ axis Currents in Stationary

reference frame respectively in A.

Stator Resistance/phase in $\Omega$.

Mutual inductance in $\mathrm{H}$

Rotor Resistance/phase in $\Omega$.

Rotor Self Inductance in $\mathrm{H}$.

Inertia of Motor in kg-m2.

Electrical Torque in N-m.

Load Torque in $\mathrm{N}-\mathrm{m}$.

\section{Modeling of Three Phase Im (Induction Motor) Mathematically}

The mathematical modelling has been developed according to the expressions by using MATLAB/SIMULINK. In reference to construct the conventional model of an IM we used to consider the three phase equations which are given below.

$$
\begin{aligned}
& V_{a s}=V_{m} \sin \left(\omega_{e} t\right) \\
& V_{b s}=V_{m} \sin \left(\omega_{e} t-\frac{2 \pi}{3}\right) \\
& V_{c s}=V_{m} \sin \left(\omega_{e} t+\frac{2 \pi}{3}\right)
\end{aligned}
$$

The synchronous rotating reference frame can be formed only by two phases (d\&q axis transformation), above voltage equations can be transferred to the $\mathrm{d}-\mathrm{q}$ axis which is given below. 


$$
\left[\begin{array}{l}
V_{\infty} \\
V_{\beta} \\
V_{0}
\end{array}\right]=\left[\begin{array}{ccc}
1 & \frac{-1}{2} & \frac{-1}{2} \\
0 & \frac{\sqrt{3}}{2} & \frac{-\sqrt{3}}{2} \\
\frac{1}{2} & \frac{1}{\sqrt{2}} & \frac{1}{\sqrt{2}}
\end{array}\right]\left[\begin{array}{l}
V_{a} \\
V_{b} \\
V_{c}
\end{array}\right]
$$

For two phase machines, we have to represent direct and quadrature axis for stator and rotor circuits such that stator circuit expressions can be developed below.

$$
\begin{aligned}
& V_{q s}^{s}=R_{s} I_{q s}^{s}+\frac{d \varphi_{q s}^{s}}{d t} \\
& V_{d s}^{s}=R_{s} I_{q s}^{s}+\frac{d \varphi_{d s}^{s}}{d t}
\end{aligned}
$$

where the quadrature \& direct axis stator flux linkages, separately. Equations (5) and (6)are further converted into synchronously rotating frame $d_{e}-q_{e}$ frame given by.

$$
\begin{aligned}
& V_{q s}=R_{s} I_{q s}+\frac{d \varphi_{q s}}{d t}+\omega_{e} \varphi d s \\
& V_{d s}=R_{s} I_{d s}+\frac{d \varphi_{d s}}{d t}-\omega_{e} \varphi d s
\end{aligned}
$$

Note that from the above equations, each and every variable are in rotating form. The end terms in above expressions represents the speed emfs because of the rotation of the axes, i.e., when $\omega \mathrm{e}=0$, the expressions return back to standstill form. The field equations in $d_{e}$ and $q_{e}$ axis includes emf's in $q_{e}$ and $d_{e}$ with an angle leading 90 . When the rotor is standstill i.e., $\omega r=0$, the rotor expressionslikely to stator expressions are described below.

$$
\begin{aligned}
& V_{q r}=R_{r} I_{q r}+\frac{d \varphi_{q r}}{d t}+\omega_{e} \varphi_{d r} \\
& V_{d r}=R_{r} I_{d r}+\frac{d \varphi_{d r}}{d t}-\omega_{e} \varphi_{d r}
\end{aligned}
$$

Such that every parameters and variables are referred to the stator. Since the rotor rotates with zero speed after some time the direct \& quadrature axes on the rotor side rotates at a speed of $\omega e-\omega r$ correlative to the rotating frame synchronously. The rotor expressions canrewrite in the form of $d_{e}-q_{e}$ axis can be shown below.

$$
\begin{aligned}
& V_{q r}=R_{r} I_{q r}+\frac{d \varphi_{q r}}{d t}+\left(\omega_{e}-\omega_{r}\right) \varphi_{d r} \\
& V_{d r}=R_{s} I_{d r}+\frac{d \varphi_{d r}}{d t}-\left(\omega_{e}-\omega_{r}\right) \varphi_{q r}
\end{aligned}
$$

The dynamic modelling of IM (induction motor) in state space form is going is developed. Therefore, it is necessary to define flux linkage variables and are given as follows. Such that the voltage equations can be modified into.

$$
\begin{gathered}
V_{q s}=R_{s} I_{q r}+\frac{1}{\omega_{b}} \frac{d F_{q s}}{d t}+\frac{\omega_{e}}{\omega_{b}} F_{d s} \\
V_{d s}=R_{s} I_{d s}+\frac{1}{\omega_{b}} \frac{d F_{d s}}{d t}+\frac{\omega_{e}}{\omega_{b}} F_{q s} \\
0=R_{r} I_{q r}+\frac{1}{\omega_{b}} \frac{d F_{q r}}{d t}+\frac{\left(\omega_{e}-\omega_{r}\right)}{\omega_{b}} F_{d r}
\end{gathered}
$$




$$
0=R_{r} I_{d r}+\frac{1}{\omega_{b}} \frac{d F_{d r}}{d t}+\frac{\left(\omega_{e}-\omega_{r}\right)}{\omega_{b}} F_{q r}
$$

The Stator and rotor flux in $\mathrm{d} \& \mathrm{q}$ (direct and quadrature) axis can be derived in terms of currents.

$$
\begin{gathered}
\varphi_{q s}=L_{l s} I_{q s}+L_{m}\left(I_{q s}+I_{q r}\right) \\
\varphi_{q r}=L_{l r} I_{q r}+L_{m}\left(I_{q s}+I_{q r}\right) \\
\varphi_{q m}=L_{m}\left(I_{q s}+I_{q r}\right) \\
\varphi_{d s}=L_{l s} I_{d s}+L_{m}\left(I_{d s}+I_{d r}\right) \\
\varphi_{d r}=L_{l r} I_{d r}+L_{m}\left(I_{d s}+I_{d r}\right) \\
\varphi_{d m}=L_{m}\left(I_{q s}+I_{q r}\right)
\end{gathered}
$$

Multiplying the above equations by $\omega_{b}$ on both sides we can get the flux linkage expressions.

$$
\begin{gathered}
F_{q s}=X_{l s} I_{q s}+F_{q m} \\
F_{q r}=X_{l r} I_{q r}+F_{q m} \\
F_{d s}=X_{l s} I_{d s}+F_{d m} \\
F_{d r}=X_{l r} I_{d r}+F_{d m}
\end{gathered}
$$

Similarly, the flux equations with reference to current can be written in the following terms.

$$
\begin{aligned}
& i_{q s}=\frac{1}{X l_{S}}\left(\varphi_{q s-} \varphi_{m q}\right) \\
& i_{d s}=\frac{1}{X l_{S}}\left(\varphi_{d s-} \varphi_{m d}\right) \\
& i_{q r}=\frac{1}{X l_{r}}\left(\varphi_{q r-} \varphi_{m q}\right) \\
& i_{d r}=\frac{1}{X l_{r}}\left(\varphi_{d r-} \varphi_{m d}\right)
\end{aligned}
$$

By substituting the above equations in the voltage as shown in above, we get the final expressions for stator and rotor voltage.

$$
\begin{gathered}
\frac{d \varphi_{q s}}{d t}=\omega_{b}\left[V_{q s}-\frac{\omega_{e}}{\omega_{b}} \varphi_{d s}+\frac{R_{s}}{X l_{s}}\left(\varphi_{m q}-\varphi_{q s}\right)\right] \\
\frac{d \varphi_{d s}}{d t}=\omega_{b}\left[V_{d s}+\frac{\omega_{e}}{\omega_{b}} \varphi_{q s}+\frac{R_{s}}{X l_{s}}\left(\varphi_{m d}-\varphi_{d s}\right)\right] \\
\frac{d \varphi_{q r}}{d t}=\omega_{b}\left[V_{q s}-\frac{\left(\omega_{e}-\omega_{r}\right)}{\omega_{b}} \varphi_{d r}+\frac{R_{r}}{X l_{r}}\left(\varphi_{m q}-\varphi_{q r}\right)\right] \\
\frac{d \varphi_{d r}}{d t}=\omega_{b}\left[V_{d f r}-\frac{\left(\omega_{e}-\omega_{r}\right)}{\omega_{b}} \varphi_{q r}+\frac{R_{r}}{X l_{r}}\left(\varphi_{m d}-\varphi_{d r}\right)\right]
\end{gathered}
$$


The equation for the torque can be evolved by, initially speed $\omega_{r}$ is considered to be constant and by deriving the voltage and current equations. Note: speed $\omega_{r}$ should not be treated as constant when it is interconnected to torque.

$$
T_{e}=T l+J \cdot \frac{d W_{m}}{d t}=T l+\left(\frac{2}{p}\right) * J * \frac{d W_{r}}{d t}
$$

$T l=$ torque.

$J=$ rotor inertia.

$W_{m}=$ speed in mechanical.

In the modeling of IM developed torque plays a major role, it can be expressed in d-q components in more general form basically it can be expressed in the vector form which is.

$$
T e=\left(\frac{3}{2}\right)\left(\frac{P}{2}\right) \varphi_{m} * I_{r}
$$

Rewriting the torque equation in the form of $d_{e}-q_{e}$ components.

$$
T e=\left(\frac{3}{2}\right)\left(\frac{P}{2}\right)\left(\varphi d m \cdot I_{q r}-\varphi_{q m} I_{d r}\right)
$$

Similarly, the torque equations of stator \& rotor in the direct and quadrature axis can be designed into.

$$
\begin{gathered}
T e=\frac{3}{2} *\left(\frac{P}{2}\right) *\left(\varphi d m . I_{q s}-\varphi_{q m} I_{d s}\right) \\
T e=\frac{3}{2} *\left(\frac{P}{2}\right) *\left(\varphi d s . I_{q s}-\varphi_{q s} I_{d s}\right) \\
T e=\frac{3}{2} *\left(\frac{P}{2}\right) * L m *\left(I_{q s} . I_{d r}-I_{d s} I_{q r}\right) \\
T e=\frac{3}{2} *\left(\frac{P}{2}\right) *\left(\varphi_{d r} . I_{q r}-\varphi_{q r} I_{d r}\right)
\end{gathered}
$$

\subsection{Simulink Model}

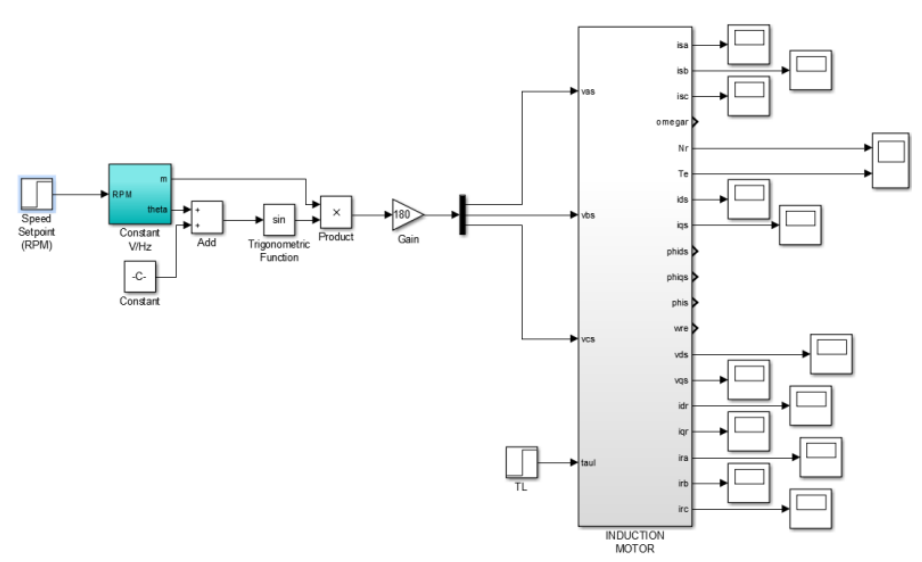

Figure 2. Simulink model for 3-phase induction motor speed control. 


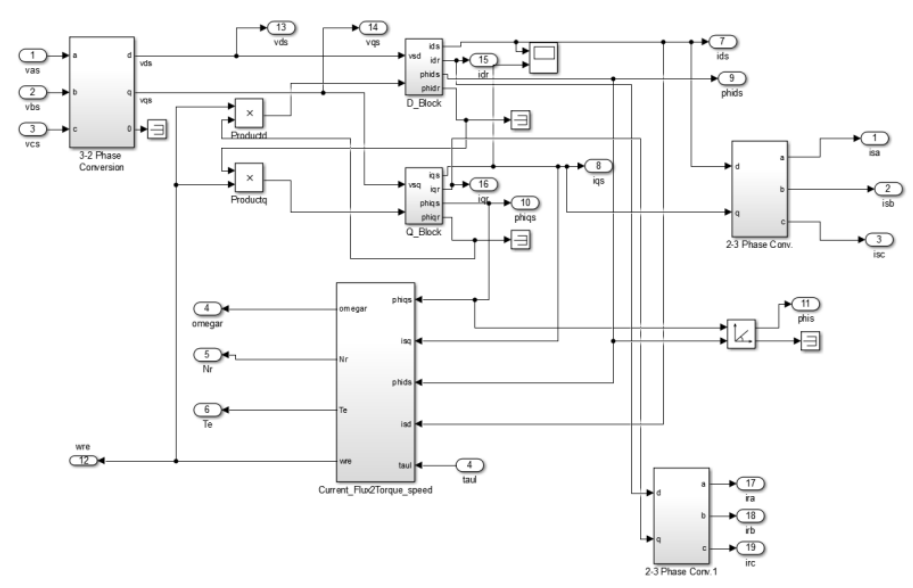

Figure 3. Internal structure of Simulink model.

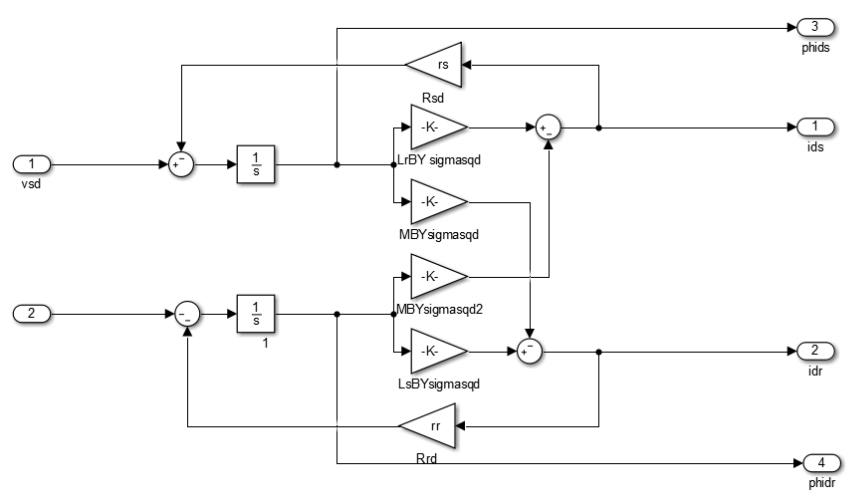

Figure 4. D-Axis block modelling.

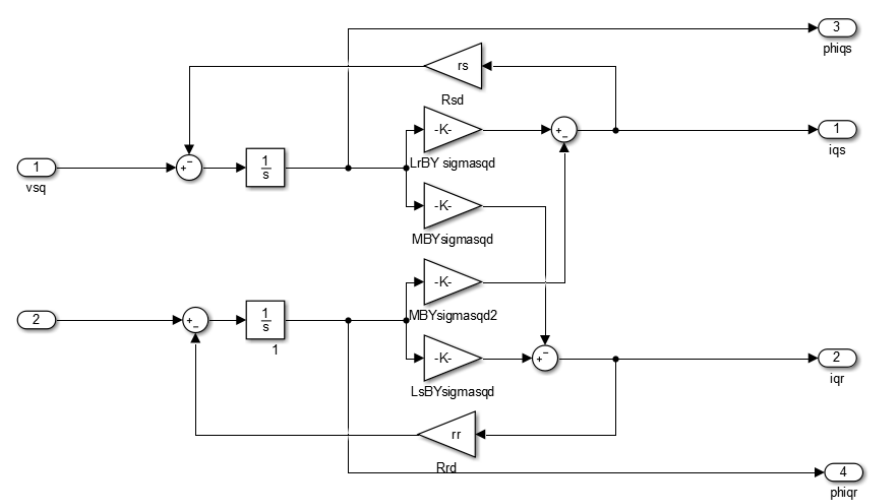

Figure 5. Q-axis block modelling.

\section{Results And Discussion}

3.1 Stator and rotor currents of A-Phase, B-Phase and C-Phase

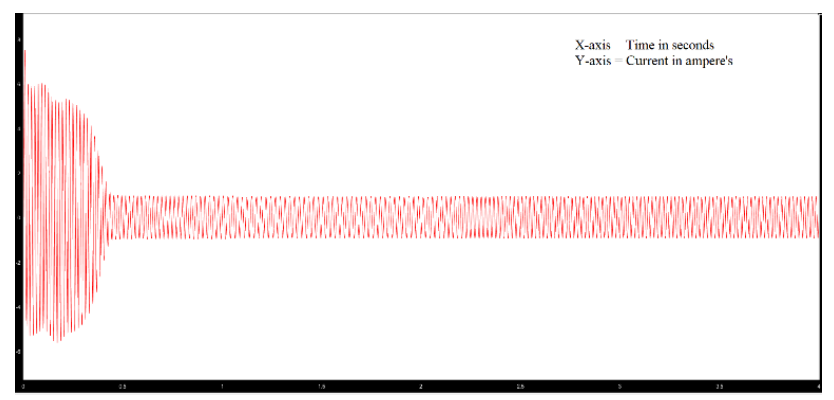


Figure 6. Stator currents for a-phase $\left(\mathrm{I}_{\mathrm{sa}}\right)$.

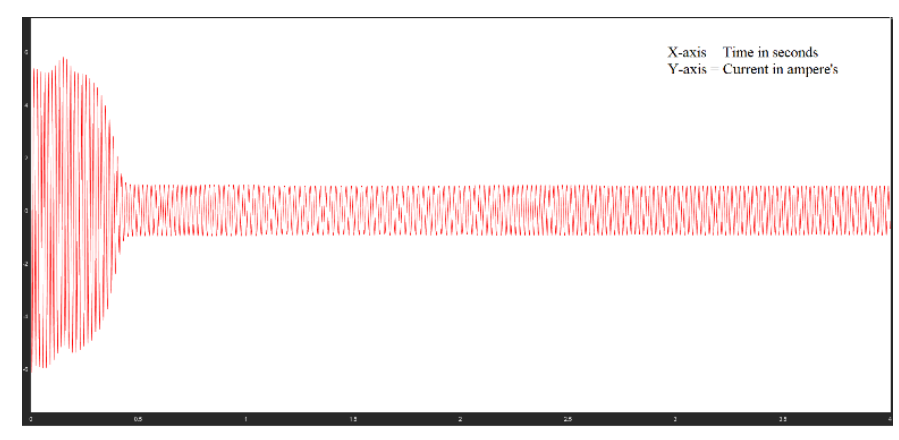

Figure 7. Stator currents for b-phase (Isb).

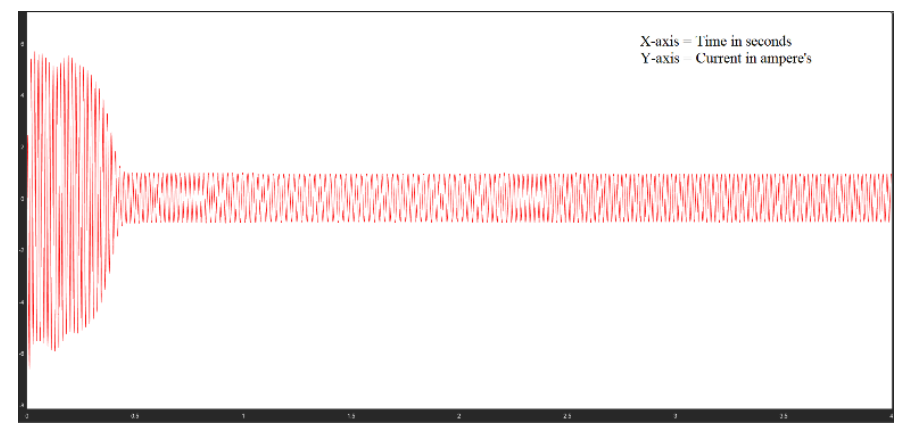

Figure 8. Stator currents for c-phase ( $\left.I_{s c}\right)$.

Fig6, Fig7, Fig8 describes the fluctuations of three phase stator axis currents with respect to the time when the sudden loading implants on the 3-phase IM(induction motor). The fluctuation is due to the sudden start of the motor which can observe up to the time $0.4 \mathrm{sec}$ from $0.4 \mathrm{sec}$ we can observe the normal current flowing through the stator.

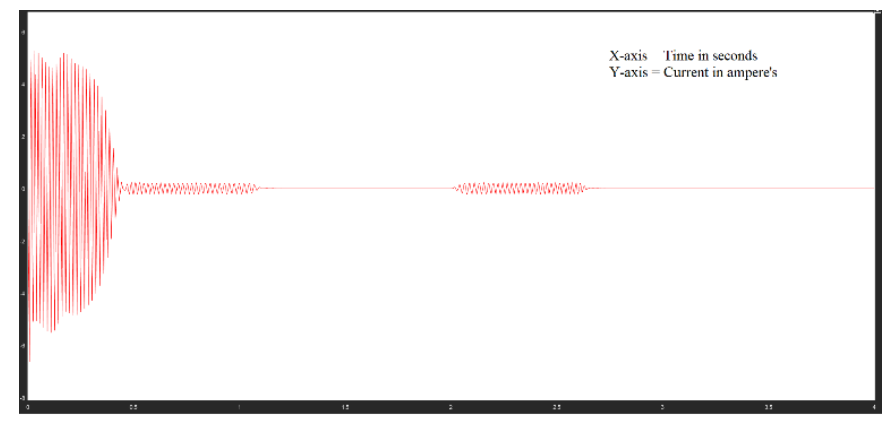

Figure 9. Rotor axis a-phase current (Ira)

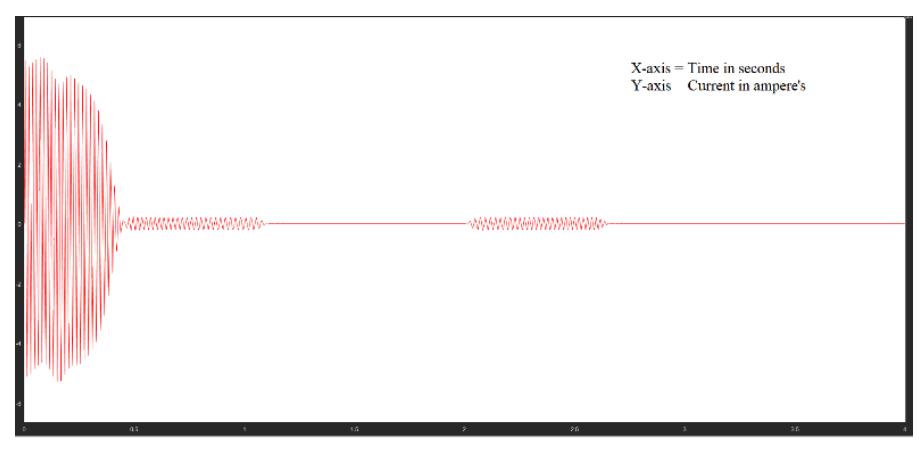

Figure 10. Rotor axis b-phase current ( $(\mathrm{r} b)$

Fig9, Fig10, Fig11 represents the fluctuations of 3-Phase rotor currents with respect to the time when the sudden loading occurs on the three-phase induction motor. The fluctuation is due to the sudden start of the motor 
which can observe up to the time $0.4 \mathrm{sec}$, due to small variation in speed it continuous to 1 and then we can observe the current without any fluctuation.

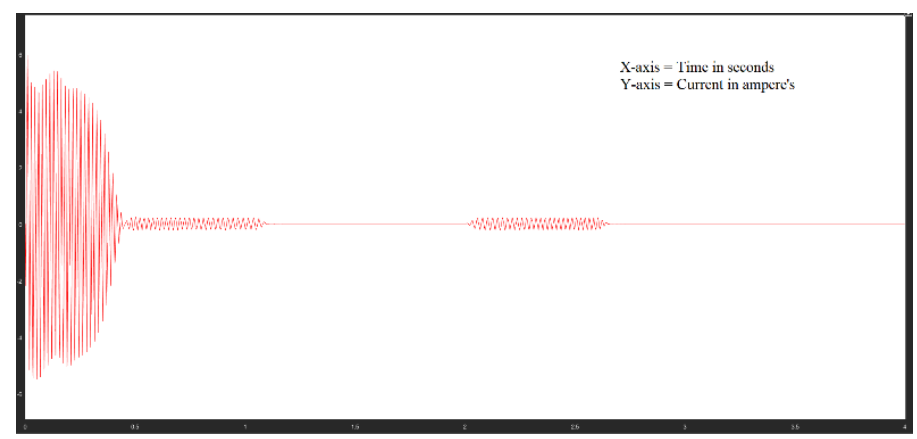

Figure 11. Rotor axis c-phase current (Irc)

\subsection{Stator and rotor currents of d-axis}

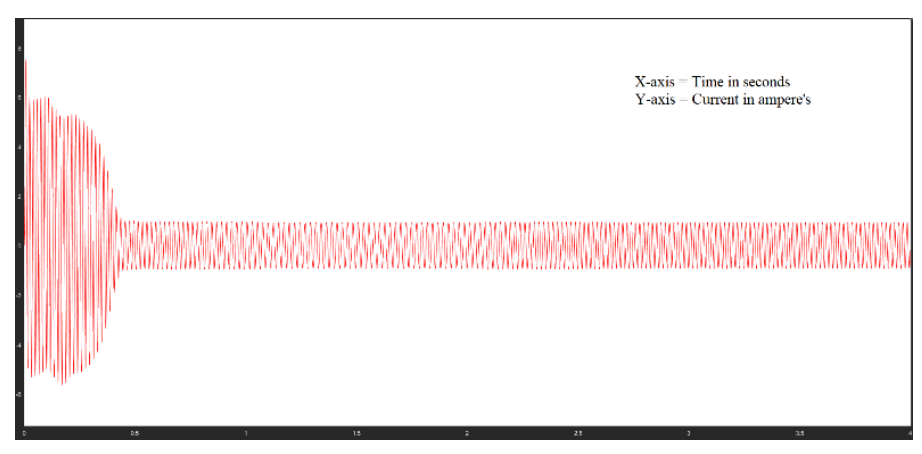

Figure 12. Direct axis current for stator $I_{\mathrm{ds}}$

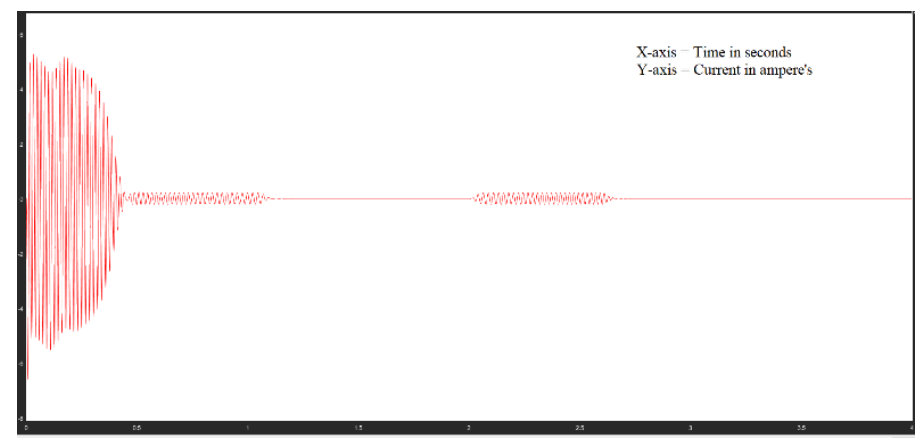

Figure 13. Direct axis currentfor rotor $\mathrm{I}_{\mathrm{dr}}$

Fig12 and Fig13 represents the fluctuations of direct axis currents of stator and rotor side whenever sudden loading occurs on the Induction motor where $\mathrm{X}$-axis shows time in seconds and $\mathrm{Y}$-axis shows current in amperes.

\subsection{Stator and rotor currents of $q$-axis}

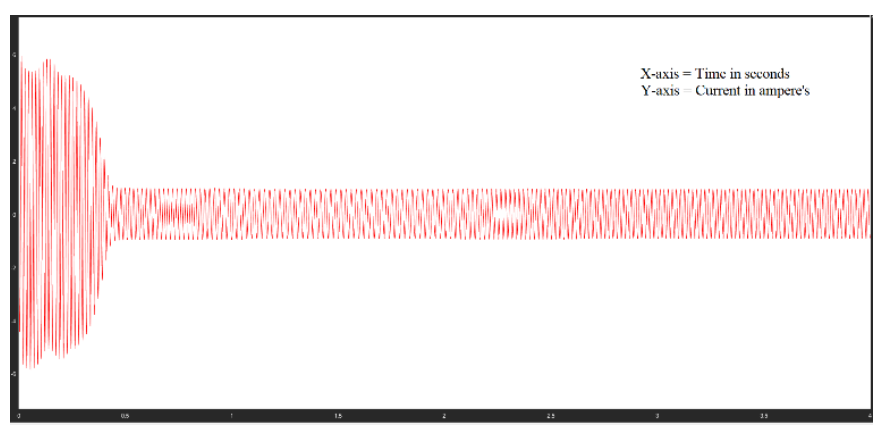

Figure 14. Stator quadrature axis current $\mathrm{I}_{\mathrm{qs}}$ 
Fig14, Fig15 shows the fluctuations of quadrature axis currents of stator and rotor side whenever sudden loading occurs on the Induction motor where $\mathrm{X}$-axis belongs to time in seconds and $\mathrm{Y}$-axis belongs to current in amperes.

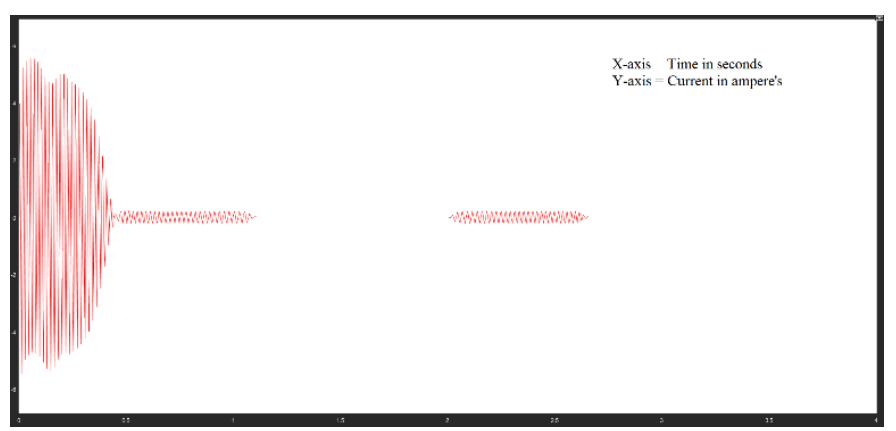

Figure 15. Rotorquadrature axis current $\mathrm{I}_{\mathrm{qr}}$

\subsection{Stator voltages of direct and quadrature axis}

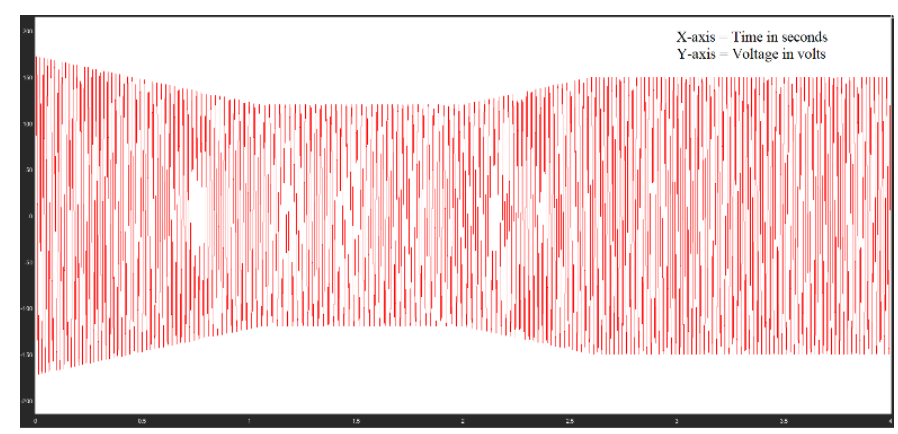

Figure 16. Stator side direct axis voltage $\mathrm{V}_{\mathrm{ds}}$

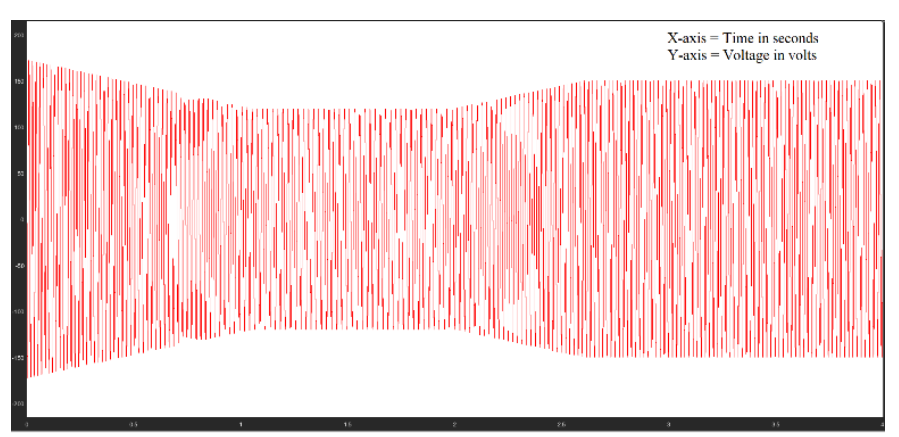

Figure 17. Stator side quadrature axis voltage $\mathrm{V}_{\mathrm{qs}}$.

The waveforms which are in Fig16 and Fig18 describes the stator voltages for direct and quadrature axis

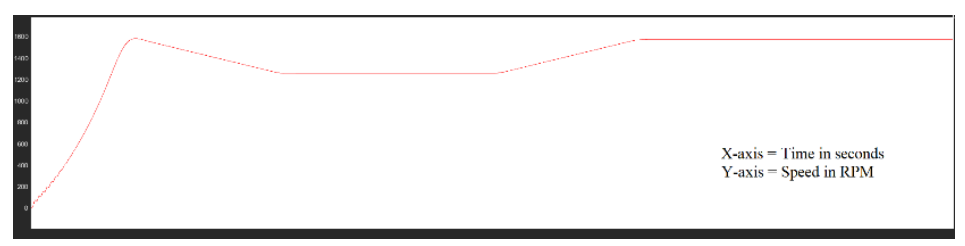

Figure 18. Speed of induction motor $\mathrm{N}_{\mathrm{r}}$

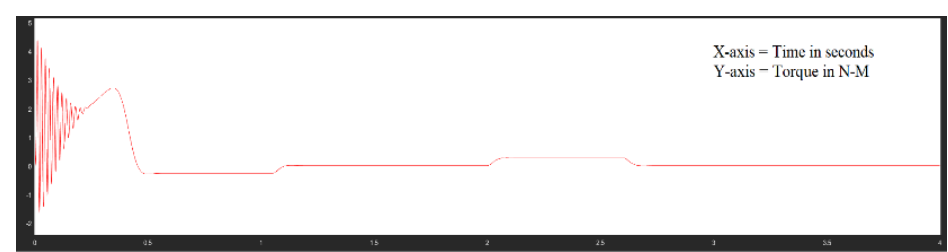

Figure 19. Torque waveform of induction motor Te. 
Fig18, Fig19 shows the speed and torque waveforms, in order to get the constant output speed, the speed control is necessary such that initially the speed and torque varies up to $2.7 \mathrm{sec}$ upon it the speed is maintained constant such that the torque also maintained constant.

\section{Conclusion}

In this paper, we are implemented the dynamic model and speed control for the 3-phase IM using the MATLAB/Simulink in the sequential manner. The updated model given adequate response in terms of speed and torque characteristics. Which can be useful in detecting the inaccuracy of the machine before it is constructed where it is used in the major sectors including traction and industrial applications. This concludes MATLAB/Simulink is an authentic and enlightened way to predict and analyze the working of three phase IM (induction motor).

\section{References}

1. Arunkarthikeyan K., and Balamurugan K. (2021) Experimental Studies on Deep Cryo Treated Plus Tempered Tungsten Carbide Inserts in Turning Operation. In: Arockiarajan A., Duraiselvam M., Raju R. (eds) Advances in Industrial Automation and Smart Manufacturing. Lecture Notes in Mechanical Engineering. Springer, Singapore. https://doi.org/10.1007/978-981-15-4739-3_26

2. Arunkarthikeyan, K. and Balamurugan, K., (2020) July. Performance improvement of Cryo treated insert on turning studies of AISI 1018 steel using Multi objective optimization. In 2020 International Conference on Computational Intelligence for Smart Power System and Sustainable Energy (CISPSSE) (pp. 1-4). IEEE.

3. Balamurugan K, Uthayakumar M, Sankar S, Hareesh US, Warrier KG. (2018) Preparation, characterisation and machining of LaPO4-Y2O3 composite by abrasive water jet machine. International Journal of Computer Aided Engineering and Technology, 10(6), pp.684-697.

4. ChinnamahammadBhasha, A., Balamurugan, K. (2020) Studies on Al6061nanohybrid Composites Reinforced with SiO2/3x\% of TiC -a Agro-Waste. Silico,. https://doi.org/10.1007/s12633-020-00758-x

5. Deepthi T, and Balamurugan K. (2019) Effect of Yttrium (20\%) doping on mechanical properties of rare earth nano lanthanum phosphate (LaPO4) synthesized by aqueous sol-gel process. Ceramics International. 45(15), pp.18229-18235.

6. Garikipati P, and Balamurugan K. (2021) Abrasive Water Jet Machining Studies on AlSi 7+ 63\% SiC Hybrid Composite. InAdvances in Industrial Automation and Smart Manufacturing, pp. 743-751, Springer, Singapore.

7. Jayanthiladevi, A., Murugan, S., \& Manivel, K. (2018). Text, images, and video analytics for fog computing. In Handbook of Research on Cloud and Fog Computing Infrastructures for Data Science (pp. 390-410).IGI Global.

8. Krause, P. C., Wasynczuk, O., Sudhoff, S. D. (2002) Analysis of ElectricMachineryandDriveSystems",IEEEPress, A John Wiley\&Sons, Inc.Publication Second Edition.

9. Liang, B. (2002) Simulation and Fault detction of three phase induction motor ", TENCON '02. Proceedings. 2002 IEEE Region 10 Conference on Computers, Communications, Control Power Engineering (3), 28-31, $1813-1817$.

10. Pavan MV, and Balamurugan K. (2020) Compressive Property Examination on Poly Lactic Acid-Copper Composite Filament in Fused Deposition Model-A Green Manufacturing Process. Journal of Green Engineering.10, pp.843-852.

11. Rajalakshmi Samaga, .B.L., Sushma. (2010) DQModelingOf Induction Motor For Virtual Flux Measurement”, Department of Electrical and ElectronicsEngineering, National Institute of Technology Karnataka, IEEE, 2010.

12. Sampathkumar, A., Murugan, S., Ahmed A., Elngar, Lalit Garg, Kanmani, R., Christy Jeba Malar, A. , (2020) A Novel Scheme for an IoT-Based Weather Monitoring System Using a Wireless Sensor Network." In Integration of WSN and IoT for Smart Cities, pp. 181-191.

13. Shahin Hedayati Kia (2007) Gearbox Monitoring Using Induction Machine Stator Current Analysis", Diagnostics for Electric Machines, Power Electronics and Drives, 2007. SDEMPED 2007. IEEE International Symposium :149-154. 